\title{
THE ELECTRIC PERCUSSION DRILL IN THEORY AND PRACTICE.
}

BY HARRY N. MARVIN.

Wherever rock is to be excavated, in mining, tunneling or quarrying, there of necessity we find the percussion drill. Until about a year ago, two types of drills held the field, the hand drill and the direct-acting steam or air drill. With the extension of electrical methods of power transmission to mining operations, came the urgent demand for an electrically operated percussion drill. The mechanical and electrical requirements of this machine are particularly severe. It is called upon to continuously endure an action that is, in almost all other machinery, studiously avoided, namely, a practically uncushioned reciprocation and a blow upon substances harder than cast-iron. The general requirements of an electric percussion drill for mining work are that it shall be light enough to be quickly handled by two or three men; it must be powerful enough to compete with an air drill that absorbs eight or ten horse power; it must be so simple in its design that it can readily be repaired by an ordinary mechanic without electrical experience; it must be so constructed that the complete machine and its several parts can be soaked in mud and water without injury ; it should be incapable of burning out ; it must be able to endure almost any amount of the roughest handling without injury, and the materials employed should be as little subject to crystallization as possible. My experience suggests the following elements of construction to be avoided:-Traveling conductors, commutating or current shifting devices, sliding contacts, spring contacts, cotton insulated wire and all insulating material capable of carbonization, switches, lamination of the moving parts, close 
fittings and joints liable to be impaired by considerable wear, all constructions liable to be impaired by careless or unskilled attention. For the benefit of those unfamiliar with the actions of the air drill, I will state that the general practice at present is to give

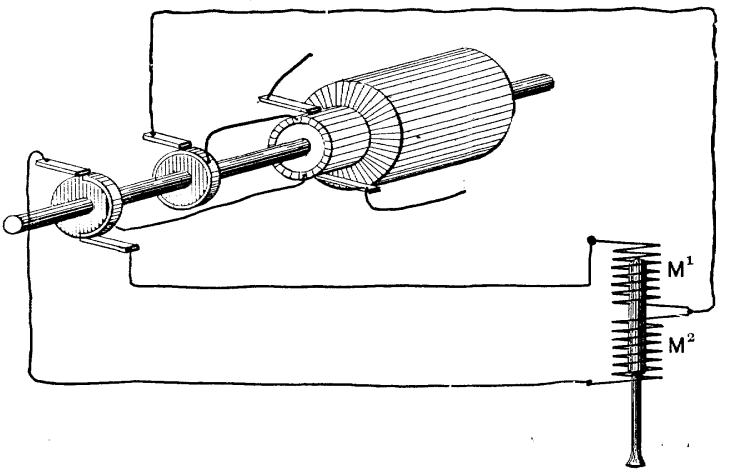

Fig. 1.

the machine a stroke of from five to seven inches, to strike as nearly as possible an uncushioned blow upon the rock and to make as many blows per minute as the power applied will develop, usually from two to four hundred per minute. It is found that a stroke of about five inches is necessary to properly free the hole from mud.

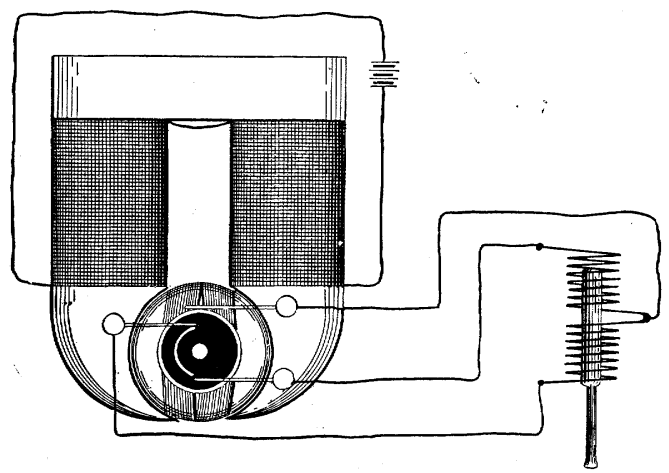

Fig. 2.

In the electrical solution of the problem, the solenoid and plunger affords the simplest method of developing this action, and most of the work in this field has been confined to this line. After much experimental work with divided solenoids and commutating 
devices mounted on the drill, I abandoned these methods, and in 1888 devised the system of operation that is at present rather well known, but for clearness this may be illustrated.

Fig. 1 shows an ordinary continuous dynamo having two oppo-

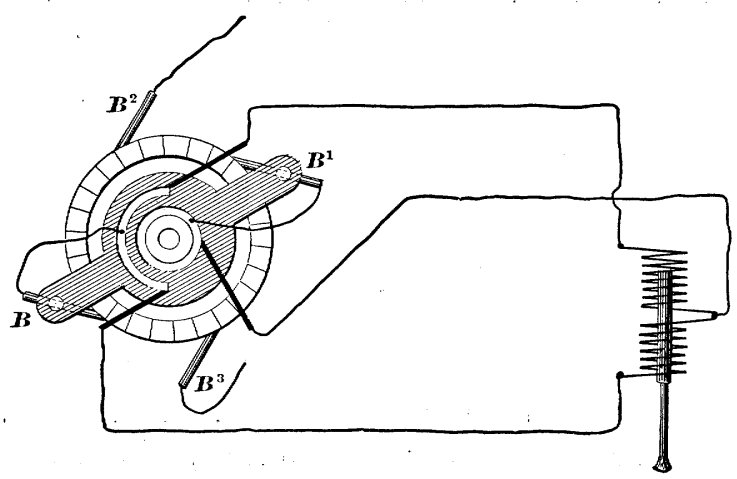

FIg. 3.

site points of its armature connected to a solid collecting ring and a half ring respectively. The outer terminals of the drill coils, $\mathrm{M}^{1}$ and $\mathrm{M}^{2}$, are connected by line wires to the two brushes alternately bearing upon the half ring. The inner terminals of the coil are joined and led to the solid ring. It appears that, as the

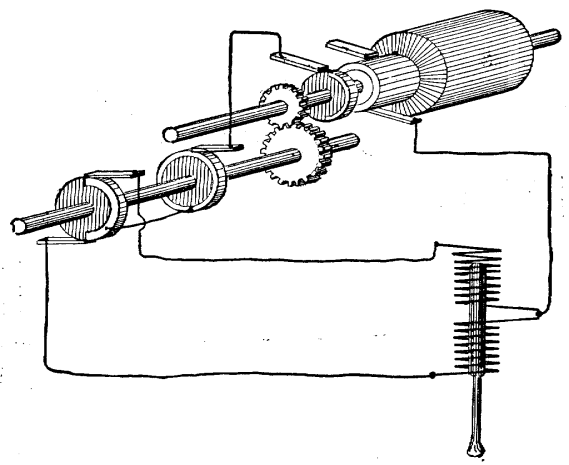

Fig. 4.

armature revolves, current impulses are directed into the drill coils in alternation, causing a reciprocation of the plunger in synchronism with the dynamo armature. It will be noticed that the action here closely resembles the action of a steam engine, force 
being exerted first in one direction and then in the other, one end of the cylinder being idle while the other end is active. Of course, connections are such that the polarity of the plunger is never reversed. This system simplifies to the utmost the construction of the drill and enables it to be so designed as to satisfy all of the

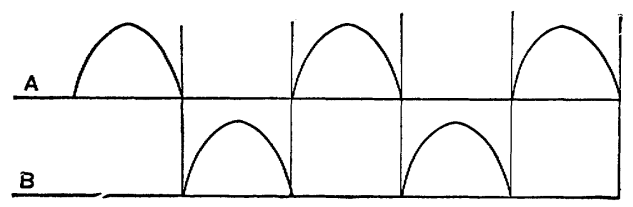

FIG. 5.

conditions before mentioned. The complications of this system are more apparent in theory than in practice. Three wires are required, but once placed they give no further trouble. The generator can be used to develop continuous current and pulsating currents at the same time if desired, but I believe that it is better practice to use a separately excited drill generator without regular commutator. The machine then becomes extremely simple, as shown by Fig. 2. I have found it desirable to run these drills at a speed of about 400 per minute, a rather slow speed for small

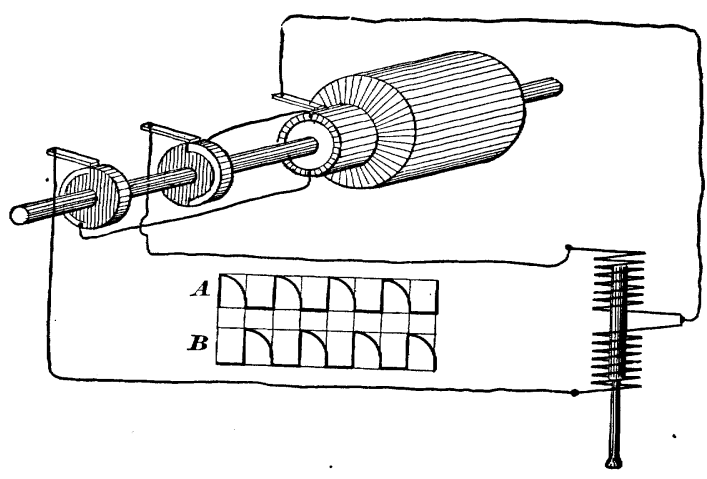

Fig. 6.

dynamos. This difficulty may be avoided at the expense of simplicity in several ways. One method is shown in Fig. 3. The regular commutator of a continuous current armature is equipped with a pair of revolving brushes, $\mathrm{B}, \mathrm{B}^{1}$, one of which connects to the solid ring of the drill circuit commutator and the other to the 
half ring. In this manner pulsations are developed in the drill circuit as the brushes $\mathrm{B}-\mathrm{B}^{1}$ are rotated, and with a frequency entirely independent of the armature speed. With this arrangement we are also able to take off 100 volt alternating currents from a commutator that is also supplying a 500 volt continuons current circuit, by spacing the brushes $\mathrm{B}$ and $\mathrm{B}^{1}$ an amount less than 180 degrees.

Another method reducing the frequency of the pulsations is shown in Fig. 4, where the drill commutator is geared to the dynamo shaft, reducing the frequency to one-half the speed of the generator.

The general character of the impressed F. M. F. in the two-drill circuit in the above systems is shown in Fig. 5, curve a showing the voltage over the upper coil and curve $\mathrm{s}$ showing the voltage over the lower coil.

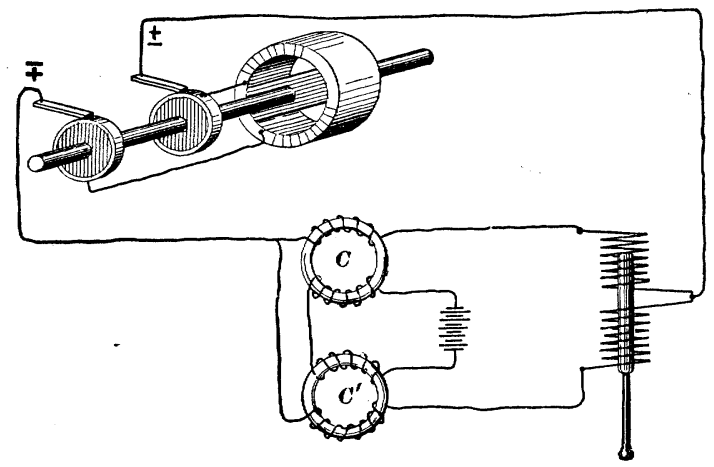

Fia. $\%$.

A method of operation by which a somewhat different curve is obtained is shown in Fig. 6. It will be noticed that here current is admitted to the drill circuits when the voltage is at a maximum the curve of impressed E. M. F being generally as shown. The general plan of admitting the current alternately to the two drill circuits, one circuit being idle white the other is active, characterize all the above methods. This may be called Plan A.

I have devised a method for efficting this without commutation, as shown in Fig. 7. Here one wire from a simple alternator is led to the drill, while the other wire passes through the si condaries of two converters $\mathrm{c}, \mathrm{c}^{\prime}$. The cores of these converters are continuously saturated by continuous currents in the primary 
coils, as shown, the windings of the converters being opposite. When current endeavors to pass through these, it is checked considerably in the converter whose magnetism it tends to reduce, and, to a much lesser degree, by the converter whose magnetism it tends to increase. A reverse current is opposed by the other converter, and thus pulsations of one polarity are strong in one coil, while those of the reverse polarity are strong in the other drill coil. This would not probably be a very efficient method.

Another general plan of drill operation, which I will call Plan B, was developed to some extent by the late Mr. Van Depoele. This plan is based on a difference of phase of current in the two coils, and is shown in its simplest form in Fig. 8. The two outer drill wires are connected to the two regular brushes of the armature $\mathrm{A}$ and the middle wire connects to the solid ring con-

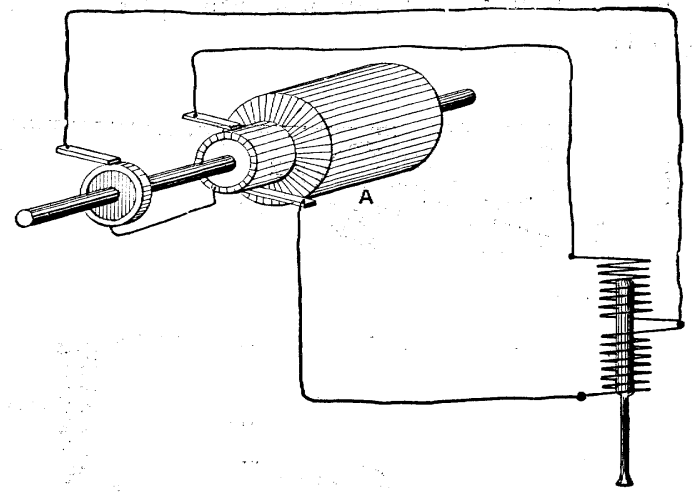

FIG. 8.

nected to one point of the armature. As the armature revolves, current rises in one drill coil and falls in the other, producing the reciprocation of the plunger. The voltage curves for this type of machine are shown by Fig. 9. An armature giving two alternating currents of 90 degrees difference of phase may also be used, but with the disadvantage of reversing the polarity of the drill plunger. The above appears to be less efficient than Plan A, for the reason that the drill coils are constantly working against each other and being heated up by current, opposing the action of the drill.

A third plan of operation, which we may call Plan $\mathrm{C}$, is that devised by Messrs. Siemens and Halske, and shown in Fig. 10. Here three coils are used in the drill, the middle coil being ex- 
cited by a continuous current and the two end coils by an alternating current of proper frequency. The function of the middle coil is to maintain a constant polarity in the bar, and the motion is effected by the effort of the two end coils. In this system both motor coils are continuously excited as in Plan B, but there

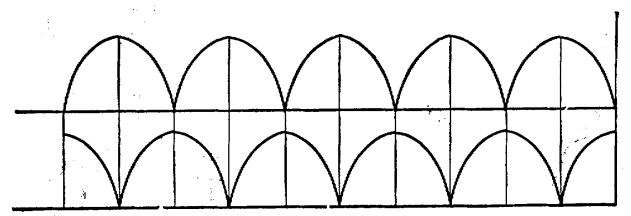

Fig. 9.

appears to be less waste of energy. Aside from the extra complication of drill construction, it is questionable if as much power can be obtained from a given weight of wire with this arrangement as can be realized on Plan A. It must be borne in inind that in these machines it is necessary to get the utmost power possible out of a given weight of copper and iron, and the heating limit is the only practical consideration. The efficiency of the machine is secondary.

Plan $\mathrm{C}$ was reduced to practice in this country by the late

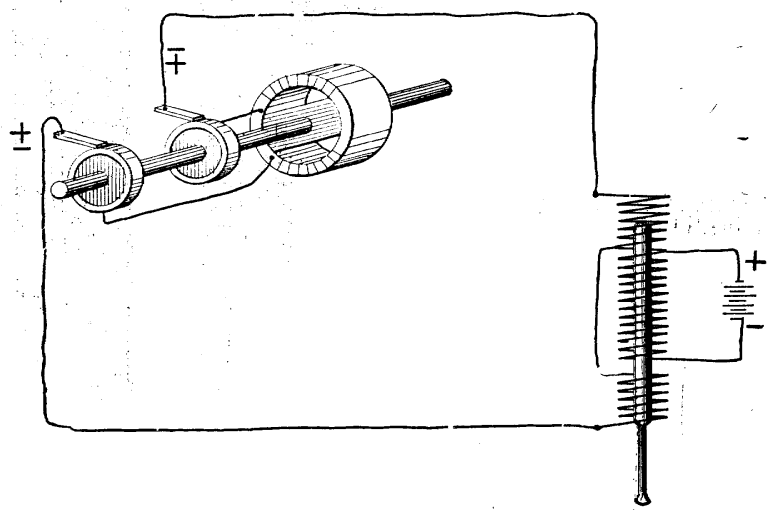

FIG. 10.

Mr. Van Depoele, who avoided the use of a fourth wire in the system by an ingenious method, shown in Fig. 11. The regular commutator $\mathrm{A}$ is supplied with rotating brushes $\mathrm{B}^{2}, \mathrm{~B}^{3}$ in addition to the regular brushes $\mathrm{B}, \mathrm{B}^{1}$. It appears that as the rotating brushes revolve, a simple alternating current flows through the 
414 MARVIN ON THE ELECTRIC PERCUSSION DRILL. [June 7,
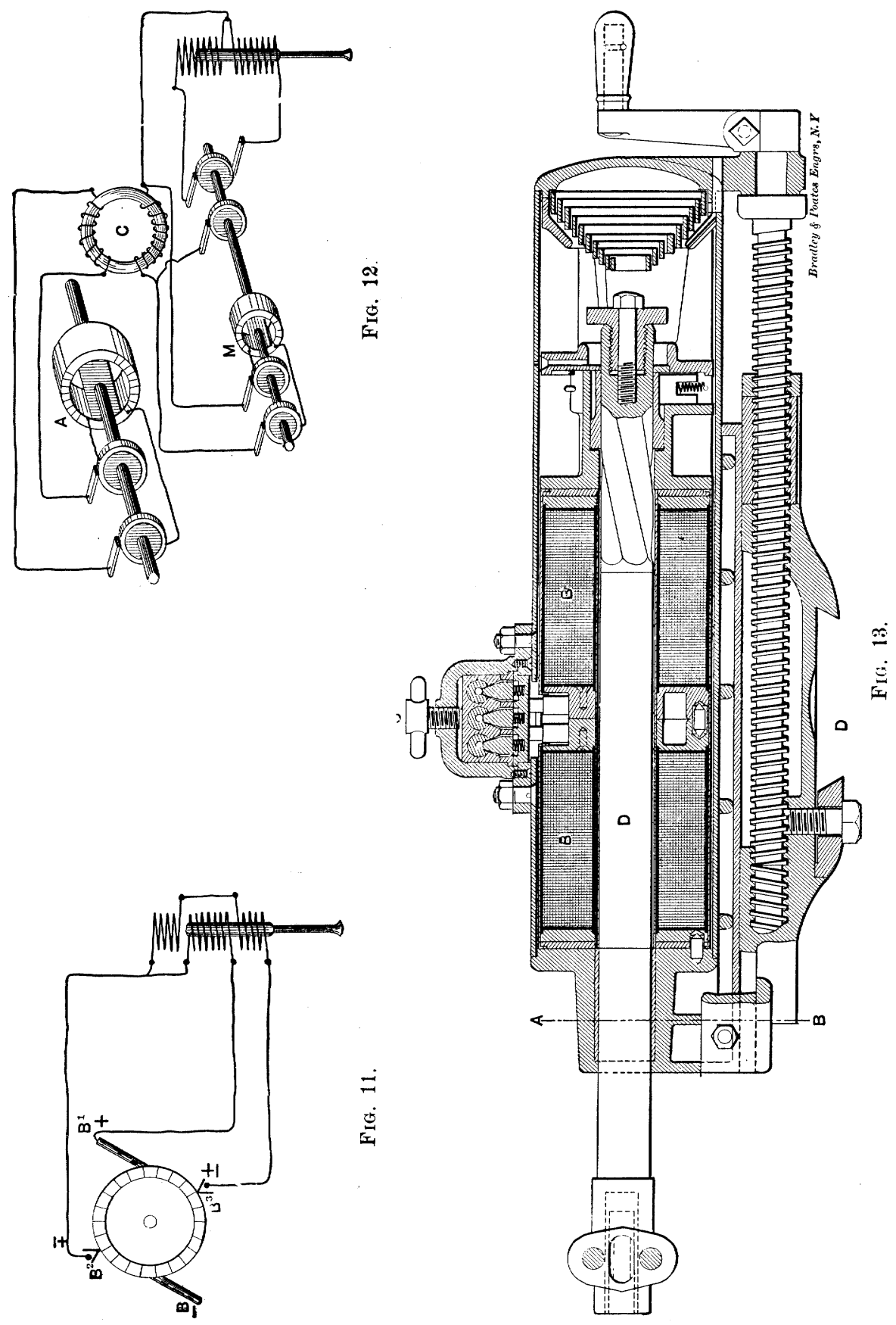
end coils of the drill, while a unidirectional pulsating current of one-half the frequency circulates in the middle coil.

The requirements of construction and service have thus far in-

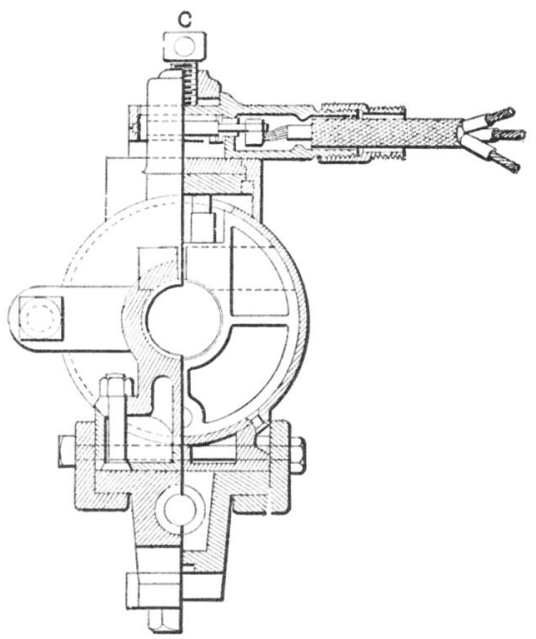

SECTION A B.

Fig. 13A.

SECTION C D.

duced me to employ a rather low voltage in the operation of drills, our present practice being to use about 100 volts alternating upon the drill. I have employed several methods of operating driils from high voltage circuits.

Referring to Fig. 3, if the regular brushes, $\mathrm{B}^{2}, \mathrm{~B}^{3}$, be connected to a 500 volt circuit, the armature will run as a motor, and if the

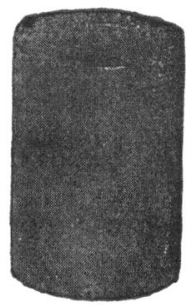

FIt. 14.

rotating brushes $\mathrm{B}, \mathrm{s}^{1}$ be spaced by a suitable amount, less than 180 degrees, they will take off the pulsating current for the drill circuit at, say, 100 volts. 

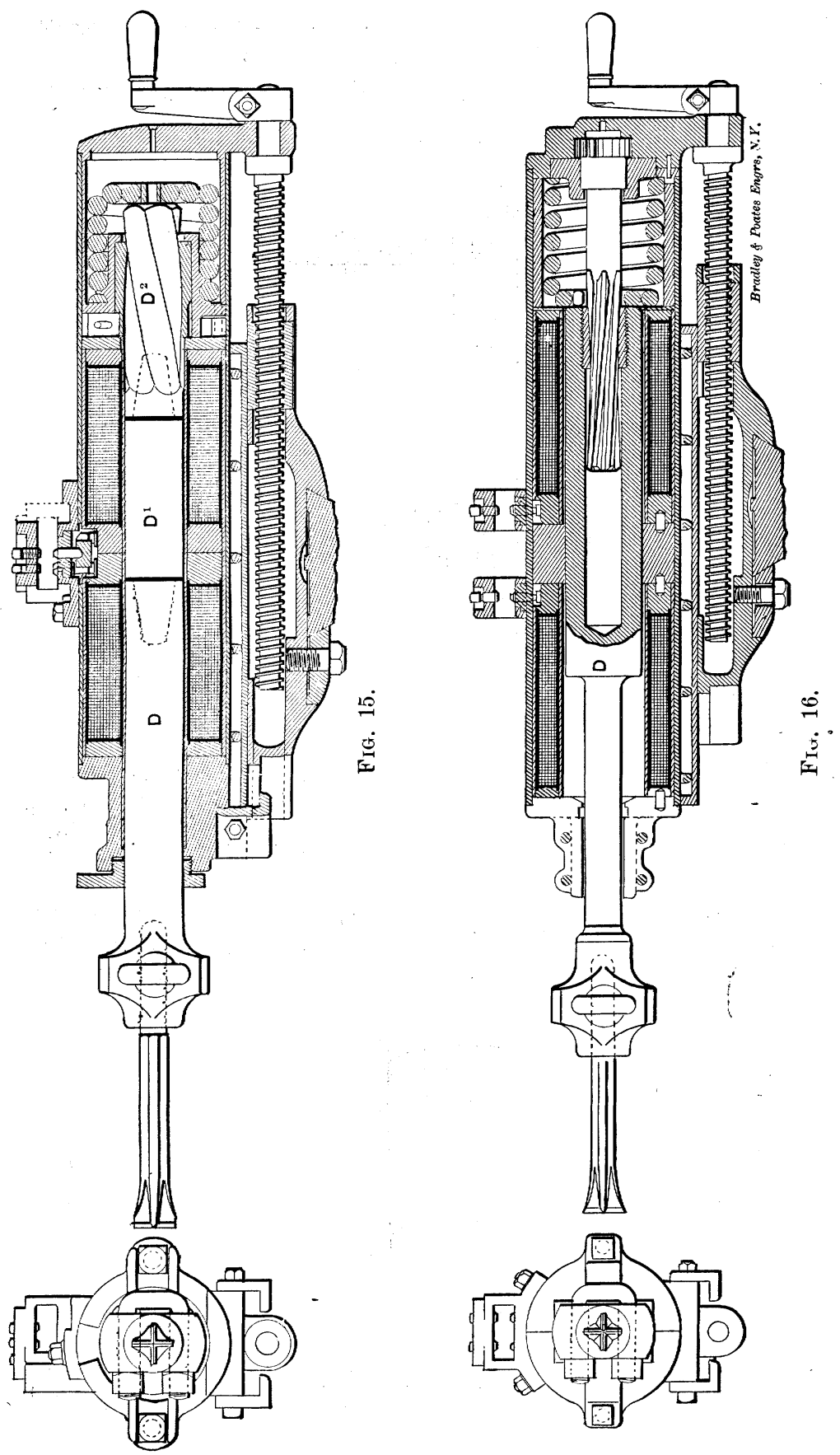
Another method is shown in Fig. 12, where a 1,000 volt alternating circuit is led from the prime generator a to the vicinity of the mine, where it passes through the primary of a converter, $\mathrm{c}$, in which the voltage is reduced to 100 volts. A small motor, $\mathbf{m}$, running in synchronism with the generator A, directs the alternate pulsations into the drill circuits.

Turning now to the drill construction, Fig. 13 shows the first form in which the percussion drill was put upon the market. This I call a Type A machine. As appears in the sketch, the machine consists of a 7 inch boiler tube provided with a suitable mounting. Within the tube are two solenoids, s, $\mathrm{B}^{1}$, a rotating device on a cushion spring. Traveling through the coils is a 2 inch plunger, $\mathrm{D}$, the middle portion of which is of iron; the upper end is of brass and is rifled, as shown, to fit the rotating device;

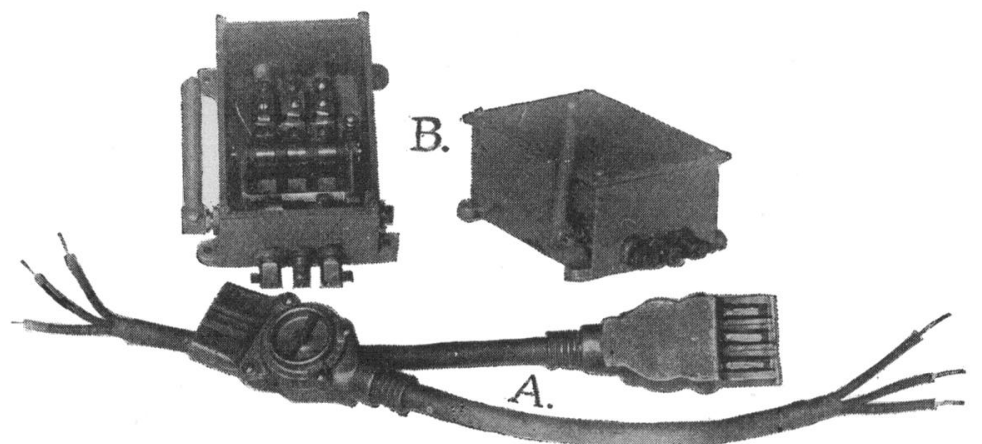

FIG. 17.

the lower end is also of brass and is enlarged at the end into a chuck to hold the bit. The three sections of the plunger are welded together. The weight of this plunger was $38 \mathrm{lbs}$. This machine was designed to make 600 blows per minute with a 3 inch to 4 inch stroke. The first of these machines to be put into a mine was that started in May, 1891, in the Black Bear Mine, at Gem, Idaho. This was, I believe, the first commercial electric percussion drill plant ever operated. During the next few months several other mines and quarries were equipped with these drills, with the general result that where the rock was not excessively hard, the work was fairly satisfactory, but in extremely hard rock several defects developed. The brass portion of the plunger would crystallize and break, a short distance above the chuck. Under the severe strain of continuous work in hard rock, the coils 
would become so heated as to ground, and the spring connections between the cable and the coils would give out. The construction of these drill coils deserves special description. Fig. 14 shows a coil complete, ready to be put into the drill. The coil is constructed as follows:-Upon a brass spool, the body and heads of which are insulated with mica, is wound a bare copper wire of square section. This wire is insulated as it is wound, with mica. The complete coil is wrapped with mica and a metal tube slipped over the whole and soldered to the coil heads, making the completed coil water-proof and heat-proof, as it is insulated with mica alone, nothing but mica and metal being used in its construction. The trouble with our first coils was that they were soldered up with a comparatively soft solder, and when the coils got very hot this solder softened, the joints opened, and oil and dirt getting in

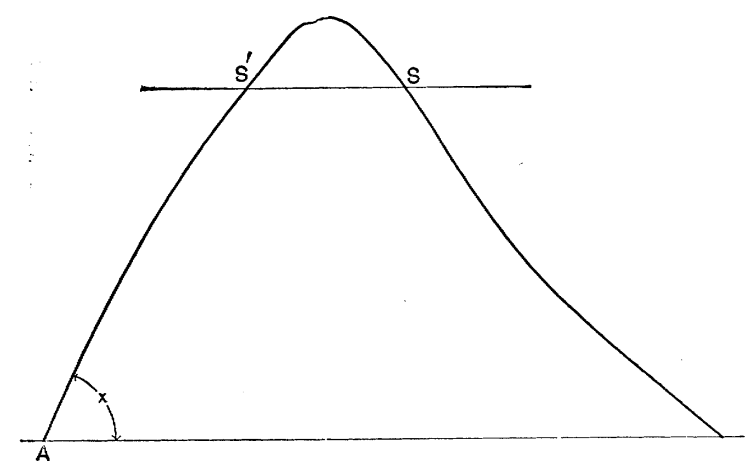

FIG. 18.

carbonized and developed a ground. As an example of the treatment these drills received, I will state that while visiting one of our drill plants that was used for railroad grading on the Great Northern Railroad, in Idaho, I saw the men dump one of these drills bodily off from a flat-car onto a dump of broken stone, down which the drill rolled some twenty feet. I might add that this was one of our most successful plants, 18 foot holes being regularly drilled in granite rock. In view of the defects mentioned, the design of the machine was altered, as shown in Fig. 15, which shows a Type B machine. The plunger has been enlarged to $2 \frac{8}{4}$ inches and is what I call the double magnet type. The forward part, $\mathrm{D}$, is now made of steel; the rifled part, $\mathrm{D}^{2}$, is also of steel, and the connecting piece, $\mathrm{D}^{1}$, is of brass. This design 
gives a solid steel chuck and brings the brass part of the plunger within the drill body. The coils are now incased in boiler tube jackets brazed up with hard spelter, and are heated to a bright red in process of manufacture. The spring connections have been abandoned, and solid set screw connections now connect the cable

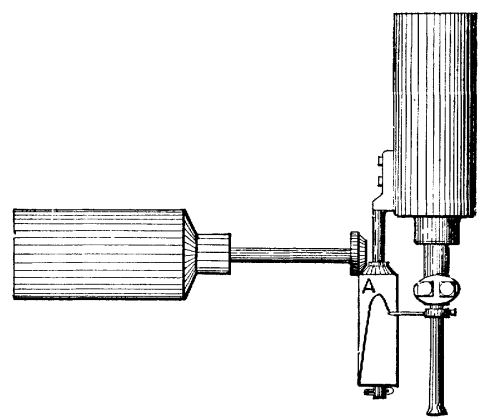

FIg. 19.

to the drill. A switch is inserted in the cable near the drill. This machine seems to overcome the defect of the old drill, and has thus far proved very satisfactory. This machine takes a stroke of about tive inches and runs at about 380 blows per minute. This longer stroke is found more effective in keeping the hole free from mud.

Fig. 16 shows a still later type of drill that I have recently built and which prumises to be much better than the others. The outside dimensions of this machine are about the same as the Type

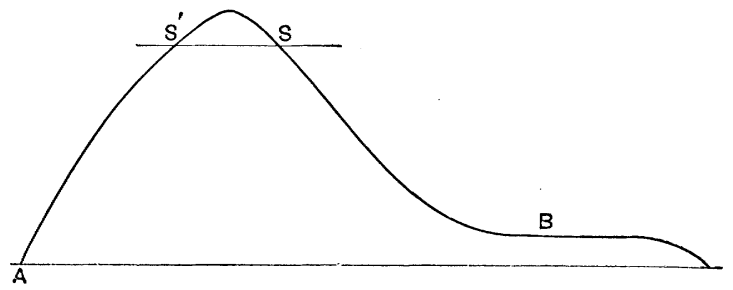

Fig. 20.

A machines, but the plunger of this machine is a solid steel forging and four inches in diameter. No brass is used in the plunger, the metal being reduced in section where it passes through the front head. The ratchet device is similar to that used in air drills and, in fact, the whole design of the machine 
quite closely follows the air drill construction. This machine takes a stroke of from $6 \frac{1}{2}$ to $7 \frac{1}{2}$ inches, and makes about 380 blows per minute. The plunger weighs $80 \mathrm{lbs}$.

Fig. 17 shows the cable connection and switch $\mathrm{A}$, and the cable fuse box $\mathrm{B}$, throngh which connection is made from the

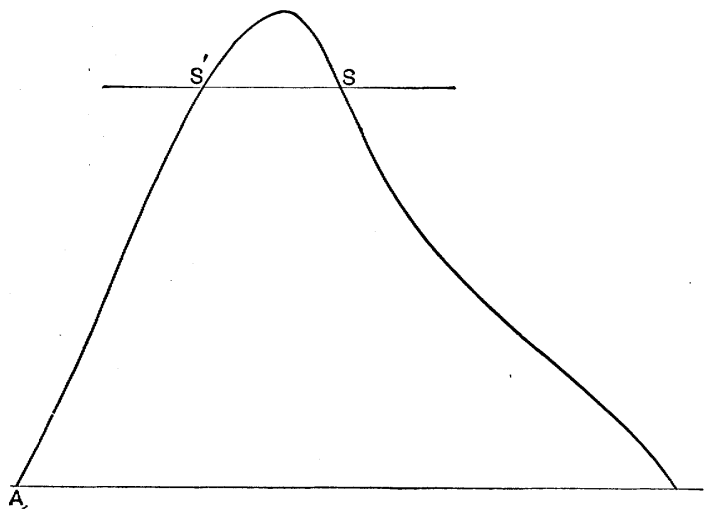

Fra. 21.

mains to the cable. A study of the operations of these machines presents many interesting features. In Fig. 18 is shown what I term an energy curve of the machine. This curve is obtained in a manner similar to an indicator card of a steam engine. Referring to Fig. 19, a is a cylinder mounted parallel to the drill rod. This cylinder is geared to the armature shaft in such a manner that it rotates in synchronism with it. A pencil carried by the drill rod rests upon the cylinder $\mathrm{A}$. It appears that as the drill rod reciprocates and the cylinder a rotates, a curve will

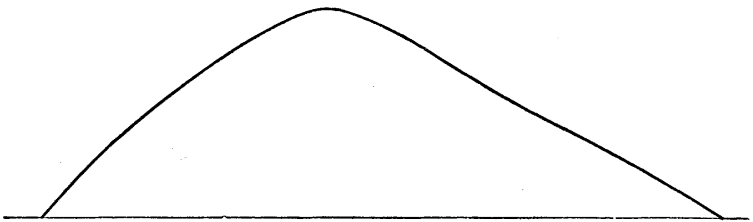

FIG. 22.

be traced by the pencil. Fig. 18 shows such a curve. The direction of motion of the paper being from left to right, it appears that the angle $\mathrm{x}$ of the curve at any point indicates the velocity of the plunger at the instant; $\mathrm{A}$ is the point where the plunger strikes the rock, and the sharp rebound is show by the angle. The 
concave character of the curve shows the backward acceleration of the plunger. The buffing spring is encountered at $\mathrm{s}$, and the angles at $\mathrm{s}$ and $\mathrm{s}^{\prime}$ show that there is little loss in the spring. The angle $\mathrm{x}$ gives the final velocity of the plunger when it strikes the rock. A simple calculation gives the energy of the blow in foot pounds. This affords a good method of comparison between different machines and conditions. The general character of the curve reveals the general action of the forces during the stroke. The curve in Fig. 20, for example, shows that the drill rebounded sharply at $\mathrm{A}$, and then stood still for a considerable time at $\mathrm{B}$,

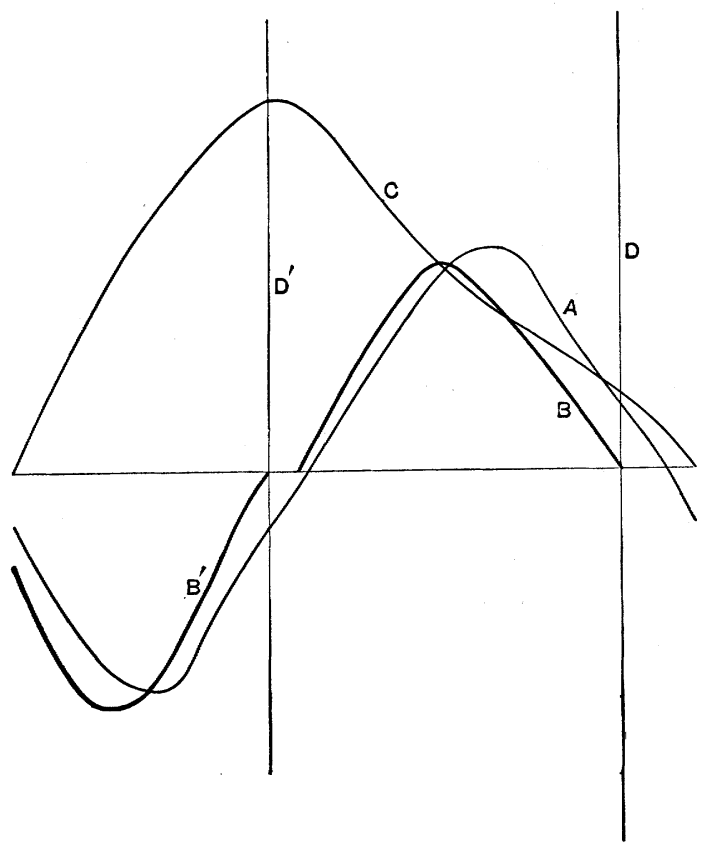

FIG. 23.

indicating that the stroke was too short for the power applied and the frequency of the stroke. On Fig. 21 we have shown the reverse conditions, where the concave character of the curve at B indicates a loss of velocity, and the length of stroke is evidently too great for the power applied. Fig. 22 shows a curve taken on a Type A drill with an 18 foot bit, drilling downward in slate rock.

The energy of the blow being determined, it can then be decided whether the drill delivers the greater amount of energy 
upon the rock by a few long strokes, or by a greater number of shorter strokes.

Some other interesting curves are shown in Fig. 23. Curve a shows the vol age on the drill circuit. Curve $\mathrm{s}$ and $\mathrm{s}^{\prime}$ the current in the two coils. Curve $\mathrm{c}$ is the energy curve. The lines $\mathrm{D}, \mathrm{D}^{\prime}$ indicate where the brushes make contact with the half ring.

The efficiency of the above machines, compared with other form of electro-motors, is of course jow, but this factor is of comparatively little moment in percussion drill work. It is far more important that the machine should be able to endure the development of a large amount of power with a small weight than that it should be highly efficient. It would seem that the general mechanical design of these machines admits of greater durability and simplicity of construction than air drills, as there are no steamtight joints required and a very great wear upon the moving parts does not reduce the effectiveness of the drill. The general flexibility of the electrical system and its peculiar adaptation to mining work are well recognized, but it has been urged that for drill work compressed air is a necessary factor for ventilation. A careful investigation of this matter reveals the fact that there is little or no weight in this objection. The instances are extremely rare where compressed air is relied upon for ventilation, and I have found few miners who considered this matter of importance.

Although the introduction of the percussion drill has been attended with many difficulties, I believe that the obstacles have been so far overcome that the machine is to-day in thoroughly practical shape.

\section{Discussion.}

Mr. Sperry :-Mr. Chairman, I have been deeply interested in the paper that has been read, and we all know Mr. Marvin's enterprise in this line for some years past, and we feel very much indebted to him for being the first one, so far as I know, to prove that a solenoid had the capacity to do the work. I remember quite a long trip I made to see one of the machines in operation. The first part of the paper is interesting as giving accurate data as to the earliest methods of circuit connection.

I also think that, among the others, the last chart presented is one of great interest to us, as presenting for the first time a curve which has been made by the machine itself. Of course, the area of the curve cannot possibly be figured in the same sense as an indicator card, but, as I take it, the deviation from a straight line 
of the upward or downward curve is the feature that is to be studied.

I would like to hear Mr. Marvin's statement with reference to the comparative merits of the three-coil and two-coil systems of operation in practice. This would be interesting and would add to our knowledge upon this point.

Mr. Marvin:-Mr. Chairman, I would say that in operating a machine with an intermittent current in the end coils, I have found very little advantage to be derived from a constant energizing coil placed between the two end coils. Of course, upon the system shown in the drawing, Fig. 9, the third or central coil is necessary to give any motion at all. You must polarize the plunger, and then one coil is supposed to pull, and the other coil to push, but my experience has led me to believe that the same amount of iron and copper will not do the same amount of work when thus distributed as when disposed in only two coils. In the three-coil drill shown, the coils are constantly energized and the heating is continuous. In the two-coil drill the coils are energized intermittently and the heating occurs only half the time,

Mr. Sperry :-Mr. Chairman, I notice that the tendency in perfecting the machine, was to make a space between the coils. Have you any measurement as to the increased reluctance incurred in thus distributing the coils?

Mr. Marvin :-I would say that the increased space between the coils in the last form of drill shown, is not an especial feature of the magnetic circuit. It is a mechanical element to afford a bearing for the plunger of the drill. I do not think that a sufficient gain in the magnetic circuit is obtained to counterbalance the increased weight of the plunger necessitated by such a construction. In fact, I have a drill about completed, with no space between the coils, but I think it will give better results.

Mr. Perry :--Mr. Chairman, I would like to ask Mr. Marvin a little further about those curves. What are the ordinates?

Mr. Marvin:-The harizontal distances represent the successive positions of the dynamo armature in its rotation. The vertical distances represent the successive positions of the plunger in its stroke.

Mr. PerRy :-Then it is not a power curve?

Mr. Marvin:-No, it does not show directly the power of the stroke. It simply shows the velocity of the plunger at any instant. The shape of that curve shows the acceleration of the plunger under the force of the coils. If you had a straight line there, it would indicate a constant velocity without acceleration, and the more the curve departs from a straight line, the more acceleration or retardation is shown.

Mr. Perry :-One feature of Mr. Marvin's drill he did not refer to, which is exceedingly interesting. It is quite as bad sometimes to strike something which has less resistance than the average, as it is to strike something harder than the average. Now, 
Mr. Marvin's drill has a peculiar property. If it strikes nothing the drill does nothing but tremble a little in space. I presume the explanation of that lies in the sluggishness of the magnetization, does it not? When it is driven in one direction the other coil holds it.

Mr. MaRvin :-The coil starts to pull it back, and you really have there an electric cushion.

Mr. Bradley :- How much power does it take, and how many inches of hard rock can you go through per minute?

Mr. Marvin:- With that last drill we absorb on the machine about $6 \frac{1}{2} \mathrm{H}$. P., that is, the large plunger drill, and we have made a record in very hard blue lime rock of drilling 56 feet in six hours, using a $2 \frac{3}{8} \mathrm{in}$. starter and drilling the holes 10 feet deep.

The following paper on "Long Distance Transmission for Lighting and Power" was then read by Mr. Charles F. Scott, of Pittsburg: 